\title{
Micetoma actinomicótico por Actinomadura madurae
}

\author{
Richard Jerez, Fabiola Schafer, Félix Fich, Patricia García, Pilar León y Sergio González
}

\section{Actinomycotic mycetoma due to Actinomadura madurae}

Mycetoma is a chronic, granulomatous, subcutaneous, inflammatory lesion caused by true fungi (eumycetoma) or filamentous bacteria (actinomycetoma). Mycetoma commonly affects young people between 20 and 40 years old. The most common affected site is the foot. The characteristic clinical triad is tumefaction, draining sinuses and discharging grains. We report a healthy 31-year-old male, with a 6-year history of a progressive inflammatory tumor associated with sinus tracts and granules on his left sole. Actinomycetoma was suspected. The clinical diagnosis was confirmed by microbiological and histopathological study. Polymerase chain reaction and DNA sequencing identified Actinomadura madurae. To our knowledge, this is the second case of mycetoma reported in Chile. Our report emphasizes the need to consider this diagnosis in patients with chronic granulomatous disease associated with sinus tracts, fistulas and grains.

Key words: Mycetoma, Actinomadura, Chile.

Palabras clave: Micetoma, Actinomadura, Chile.

\section{Introducción}

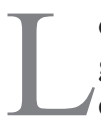
os micetomas son lesiones inflamatorias crónicas, granulomatosas y supurativas que pueden ser causadas por hongos (eumicetoma) o bacterias (actinomicetoma). Clínicamente se caracteriza por la formación de nódulos, abscesos, trayectos fistulosos y zonas de fibrosis que originan una induración de consistencia leñosa. Pueden comprometer la piel, tejidos blandos, huesos y articulaciones. A través de las fístulas drenan secreción purulenta o sero-sanguinolenta con gránulos de colores y de dimensiones variables, que corresponden a microcolonias del agente causal ${ }^{1}$. Los micetomas causados por hongos se presentan mayoritariamente en áreas tropicales, en cambio, los actinomicetomas se pueden presentar en cualquier parte del mundo ${ }^{2}$.

Los micetomas son más frecuentes en hombres, con una relación de 3 a 5:13 y los actinomicetomas producidos por Actinomadura madurae son más frecuentes en muje$\mathrm{res}^{4}$. Son más comunes en individuos que se encuentran expuestos al medio ambiente por actividades al aire libre como agricultores, pastores y cazadores ${ }^{5}$; sin embargo, también se puede observar en personas que trabajan en ciudades, víctimas de accidentes de tránsito o viajeros a zonas endémicas.

La enfermedad usualmente afecta a adultos entre 20 y 40 años; no obstante, puede observarse en niños $y$ ancianos en regiones endémicas ${ }^{6}$. No es considerada una enfermedad transmisible de animal a humano o de humano a humano.

En Chile existen escasos casos descritos de etiología bacteriana $^{7-8}$. A continuación se presenta un caso de micetoma actinomicótico causado por Actinomadura madurae.

\section{Caso clínico}

Paciente varón de 31 años de edad, sin antecedentes mórbidos, proveniente de Rancagua, que consultó por una lesión plantar izquierda; con seis años de evolución, de crecimiento progresivo y doloroso, que le dificultaba la deambulación. Trabajaba como repartidor de pizzas y no presentaba antecedentes de traumatismos o viajes al extranjero. Había recibido antimicrobianos orales y parenterales por una semana sin respuesta clínica. Al examen físico se observó una tumoración mal delimitada, asociada a trayectos sinuosos y fistulosos, con salida de material hemo-purulento y extrusión de gránulos pequeños color blanco amarillento en la planta izquierda (Figuras 1A y 1B). No se observaron otras lesiones al examen físico. Se planteó el diagnóstico probable de micetoma y se realizó una biopsia de la piel que fue enviada para estudio bacteriológico y micológico. La tinción de Gram mostró bacilos grampositivos ramificados, no ácido alcohol resistente (Figura 2A) y los medios de cultivos (Lowenstein Jensen, caldo cerebrocorazón y Sabouraud glucosado) mostraron desarrollo de colonias de aspecto rugoso y cerebriforme de color blanco nacarado (Figura 2B). Además se realizó estudio histológico donde se observaron gránulos basófilos con fenómeno de Splendori-Hoeppli e inflamación neutrofílica perifocal (Figura 2C). A mayor aumento se identificaron gránulos con bacterias filamentosas grampositivas en su interior compatibles con Actinomyces spp. (Figura 2D). Se realizó RPC universal y posterior secuenciación a las colonias aisladas identificándose Actinomadura madurae. (Departamento de Laboratorios Clínicos y Microbiología de la Pontificia Universidad Católica de Chile). No fue
Universidad de La Frontera. Temuco, Chile.

Facultad de Medicina Departamento de Especialidades Médicas (FS)

Pontificia Universidad Católica de Chile.

Facultad de Medicina

Departamento de Dermatología (RJ, FF).

Departamento de Laboratorios Clínicos y Microbiología (PG, PL) Departamento de Anatomía Patológica (SG)

Recibido: 10 de mayo de 2011 Aceptado: 15 de junio de 2012

Correspondencia a: Fabiola Schafer fdschafe@gmail.com 


\section{Caso Clínico}
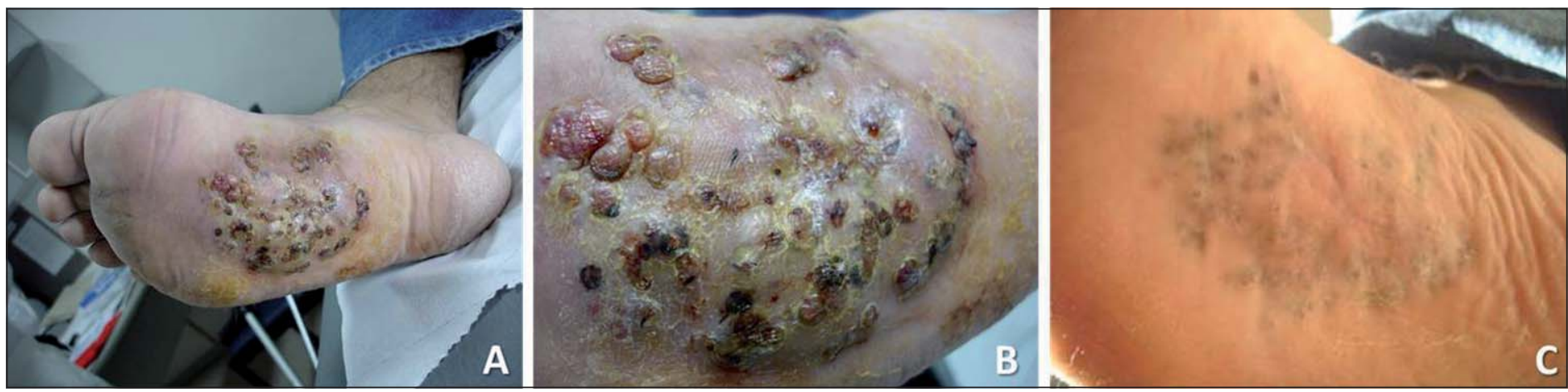

Figura 1. A) Tumoración plantar izquierda. B) Tumor con trayectos sinuosos y fistulosos, con salida de material hemopurulento y extrusión de gránulos de color blanco amarillento. C) Región plantar después del tratamiento antimicrobiano.
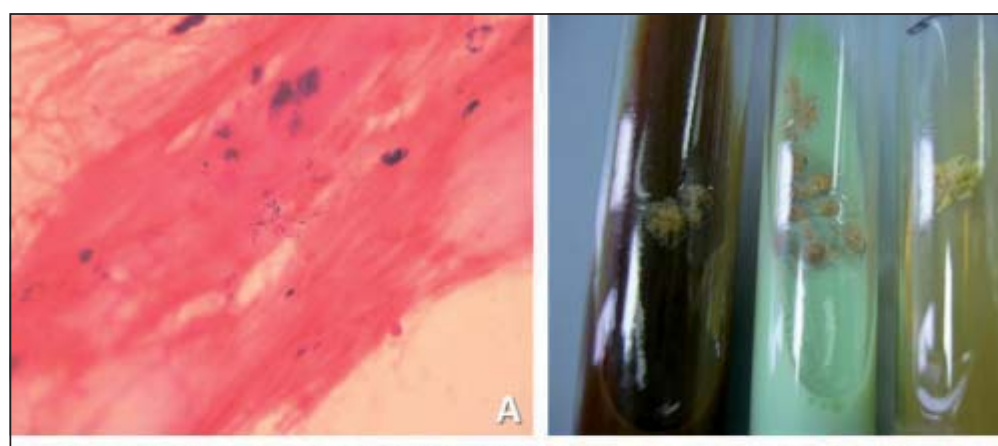

B

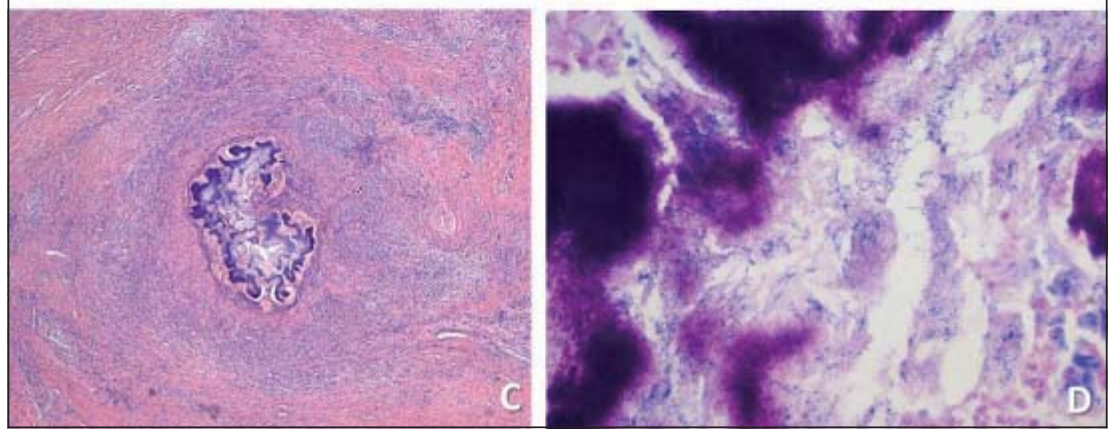

Figura 2. A) Tinción de Gram con bacilos grampositivos ramificados, no ácido alcohol resistente. B) Medios de cultivos Lowenstein Jensen, caldo cerebro-corazón y Sabouraud glucosado: desarrollo de colonias de aspecto rugosos y cerebriformes de color blanco nacarado. C) Estudio histológico: gránulo basófilo con fenómeno de Splendori-Hoeppli e inflamación neutrofílica perifocal. D) Bacterias filamentosas grampositivas compatibles con Actinomyces spp. (400x).

posible realizar estudio de susceptibilidad antimicrobiana por su dificultad de crecimiento en el laboratorio. Estudios adicionales como radiografía y ecotomografía del pie izquierdo no mostraron compromiso extracutáneo. El estudio de inmunidad fue normal. El paciente fue tratado con cotrimoxazol (800/160 mg), dos veces al día, por 12 meses, presentando una excelente evolución sin necesidad de manejo quirúrgico (Figura 1C). No hubo complicaciones o reacciones adversas asociadas al tratamiento. Después de tres años de seguimiento clínico, el paciente no ha presentado recidiva de la lesión.

\section{Discusión}

Los micetomas son poco frecuentes en nuestro país. En general, son encontrados principalmente en regiones próximas al trópico de Cáncer, en países de climas tropicales y subtropicales tales como Sudán, Somalia, Senegal, India, Yemen, México, Venezuela, Colombia y Argentina. Los países con mayor incidencia son relativamente áridos, con estaciones lluviosas durante 4-6 meses al año, una humedad relativa del aire entre 60 y $80 \%$ y temperaturas entre 30 y $37^{\circ} \mathrm{C}$. Sin embargo, casos esporádicos han sido descritos en Estados Unidos de América y Europa ${ }^{9}$.

La causa más común de micetoma en el mundo es el eumicótico, particularmente Madurella mycetomatis, que llega a 70\% de los casos en regiones de África Central. Existe un predominio de ciertos agentes según la región, p. ej. en América Central y México el micetoma es causado más comúnmente por actinomices como Nocardia brasiliensis, Streptomyces somaliensis, A. madurae y Actinomadura pelletieri y en E.U.A es causado por el hongo Pseudallescheria boydii 9 .

El micetoma, sea actinomicótico (bacterias) o eumicótico (hongos verdaderos), es un proceso granulomatoso crónico, generalmente unilateral y subcutáneo. La tríada clínica característica es un aumento de volumen del tejido afectado, trayectos sinuosos y descarga de gránulos. Inicialmente se produce una pápula o nódulo indoloro en el sitio de inoculación. Posteriormente, aparecen nuevas lesiones y trayectos fistulosos que se intercomunican entre sí, drenando gránulos de diferente color, en forma crónica. Al evolucionar los nódulos forman cicatrices retráctiles ${ }^{1}$ En algunas ocasiones invaden estructuras subyacentes, causando periostitis y osteomielitis con formación de pequeñas cavidades óseas $(2-10 \mathrm{~mm})$. El compromiso de nervios y tendones es muy infrecuente y ocurre en lesiones extensas y de larga data. La superficie de la piel se observa brillante con hiperhidrosis local y frecuentemente hiperpigmentada.

El hábitat natural de A. madurae es la tierra y los ve- 


\begin{tabular}{|ll|}
\hline \multicolumn{2}{|c|}{ Tabla 1. Localización de micetomas } \\
\hline Frecuencia & Localización \\
\hline Sitios comunes & Pies $(70-80 \%)$ \\
& Manos $(12 \%)$ \\
& Piernas \\
& Rodillas \\
Sitios comunes en regiones altamente & Brazos \\
endémicas & Cabeza/cuello \\
& Muslos \\
& Periné \\
Sitios infrecuentes & Tórax \\
& Pared abdominal \\
& Hueso facial \\
& Mandíbula \\
& Párpados \\
& Senos paranasales \\
& Vulva \\
& Órbita \\
& Escroto \\
\hline
\end{tabular}

getales. Cuando se produce un traumatismo que ocasiona pérdida de continuidad de la piel se facilita el ingreso del agente causal al organismo, teniendo mayor riesgo las personas que habitan en zonas rurales y que caminan descalzos. A pesar de la inoculación del agente causal en la zona afectada, el antecedente de traumatismo está presente en sólo un tercio de los $\operatorname{casos}^{10}$. Debido a que el período de incubación es variable y no bien definido (algunos inician los síntomas después de varias semanas o incluso después de años), sólo un pequeño porcentaje de los pacientes recuerda este antecedente ${ }^{9}$.

El rango de edad varía entre 31 y 45 años, siendo inusual después de los 60 años. El sitio más frecuente de ubicación son los pies (70-80\%), seguido por las manos $(12 \%)$, piernas y rodillas (Tabla 1). Aquellos infectados con Actinomyces spp. tienen una evolución más rápida y progresiva, con inflamación, destrucción local y rápida invasión ósea comparada con pacientes infectados con micetomas eumicóticos los que son bien delimitados, de lento crecimiento y encapsulados (Tabla 2$)^{9}$.

Existen por lo menos 20 especies de actinomicetos y hongos superiores que pueden provocar micetomas. Éstos se organizan en agregados de hifas o filamentos bacterianos, constituyendo los característicos gránulos excretados a través de las fístulas, que pueden ser de diferente tamaño, color y consistencia dependiendo de la especie causante ${ }^{11}$. Estas características permiten hacer alguna aproximación etiológica. Los gránulos rojos son siempre actinomicóticos, a diferencia de los gránulos negros que son siempre fúngicos; en los amarillos o blancos el agente causal debe ser identificado por histología y microbiología (Tabla 3).

En el estudio histopatológico de los gránulos actinomicóticos se observan filamentos de $<1 \mu \mathrm{m}$ de diámetro
Tabla 2. Tabla comparativa entre micetoma eumicótico y actinomicótico

\begin{tabular}{|c|c|c|}
\hline Enfermedad & Eumicetoma & Actinomicetoma \\
\hline Agente causal & Hongos & Bacterias \\
\hline Lesión & Encapsulada, delimitada & Difusa, mal delimitada \\
\hline Trayectos fistulosos & Pocos & Muchos \\
\hline Color gránulos & $\begin{array}{l}\text { Diversos, predominantemente blancos } \\
\text { o negros }\end{array}$ & Diversos, nunca negros \\
\hline Curso & Lento y progresivo & Inflamatorio y rápido \\
\hline Compromiso óseo & Tardío & Rápido \\
\hline $\begin{array}{l}\text { Cavidades a la } \\
\text { radiografía }\end{array}$ & Escasas en número, grandes & $\begin{array}{l}\text { Múltiples, pequeñas a excepción de } \\
\text { Actinomadura madurae }\end{array}$ \\
\hline \multicolumn{3}{|l|}{ Tratamiento } \\
\hline Fármacos & |traconazol/ketoconazol & $\begin{array}{l}\text { Amikacina+cotrimoxazol } \\
\text { Dapsona/rifampicina }\end{array}$ \\
\hline Manejo de elección & Cirugía + antifúngicos & $\begin{array}{l}\text { Sólo manejo médico es suficiente en la } \\
\text { mayoría de los casos }\end{array}$ \\
\hline Sólo cirugía & Recurrencia 90\% & No indicada \\
\hline Sólo médico & $\begin{array}{l}\text { Mejoría parcial } \\
\text { Previo o posterior al manejo quirúrgico }\end{array}$ & Útil en la mayoría de los casos \\
\hline Tratamiento exitoso & $\begin{array}{l}\text { Diagnóstico precoz y combinación de } \\
\text { antifúngicos y cirugía }\end{array}$ & $\begin{array}{l}\text { Diagnóstico precoz y antimicrobianos } \\
\text { por tiempo prolongado }\end{array}$ \\
\hline
\end{tabular}

Tabla 3. Características de los gránulos según el agente etiológico

\begin{tabular}{|ll|}
\hline Agente etiológico & Color de los gránulos \\
\hline Streptomyces somaliensis & Amarillo a café \\
\hline Actinomadura madurae & Blanco-amarillo o rosado \\
\hline Actinomadura pellitieri & Rojo \\
\hline Actinomyces israelii & Blanco a amarillo \\
\hline Nocardia asteroides & Blanco \\
\hline Nocardia brasiliensis & Blanco \\
\hline Nocardia caviae & Blanco a amarillo \\
Nocardia farcinica & Blanco a amarillo \\
\hline Nocardia transvalensis & Blanco \\
\hline Nocardia dassonvillei & Crema \\
\hline
\end{tabular}

(Figura 2D) y granulomas rodeando a los gránulos. Para algunos agentes causales como Actinomadura mycetomatis, Streptomyces somaliensis, Actinomadura madurae, y Actinomadura pelletieri, la histopatología del gránulo permite identificar la especie, mientras que para otros agentes sólo permite definir el género. En general, el cultivo es necesario para identificar la especie ${ }^{10}$. En la actualidad, el empleo de RPC universal con amplificación y secuenciación de nucleótidos del gen que codifica para 
Tabla 4. Diagnóstico diferencial de las micosis subcutáneas

\begin{tabular}{|c|c|c|}
\hline Infección & Agente causal & Manifestaciones clínicas \\
\hline Cromoblastomicosis & $\begin{array}{l}\text { Cladosporium (Cladophialophora) carrionii, Fonsecaeae } \\
\text { compacta, F. pedrosoi, Phialophora verrucosa, Rhinocladiella, } \\
\text { N. aquaspera }\end{array}$ & $\begin{array}{l}\text { Placas verrucosas o nódulos en pies, piernas, brazos y tronco superior que crecen } \\
\text { agrupadas como grandes placas verrucosas e hiperqueratósicas con cicatriz central, } \\
\text { ulceración y áreas quísticas }\end{array}$ \\
\hline Lobomicosis & Lacazia (Loboa) loboi & $\begin{array}{l}\text { Placas verrucosas o de aspecto queloideo en áreas expuestas (cara, orejas, tronco) } \\
\text { que crecen y se ulceran. Pruriginosas con nódulos secundarios }\end{array}$ \\
\hline Micetoma & $\begin{array}{l}\text { Eumicóticos (hongos) } \\
\text { Actinomicóticos (bacterias) }\end{array}$ & $\begin{array}{l}\text { Nódulo firme que evoluciona a múltiples nódulos y pápulas con drenaje fistuloso } \\
\text { crónico, excreción de gránulos y aumento de volumen de tejidos afectados, com- } \\
\text { promiso óseo adyacente }\end{array}$ \\
\hline Paracoccidioidomicosis & Paracoccidioides brasiliensis & $\begin{array}{l}\text { Lesiones orales son comunes desde pápulas agrupadas hasta úlceras, nódulos, } \\
\text { placas y lesiones verrucosas (principalmente diseminación hematógena por foco } \\
\text { primario pulmonar) }\end{array}$ \\
\hline Feohifomicosis & Bipolaris spp., Exophiala jeanselmei, Wangiella dermatitidis & $\begin{array}{l}\text { Quiste inflamatorio único en la zona proximal de extremidades que interfiere con } \\
\text { la movilidad de la articulación }\end{array}$ \\
\hline Rinosporidiosis & Rhinosporidium seeberi & Pólipos grandes color piel en nariz \\
\hline Esporotricosis & Sporothrix schenckii & Nódulos en las manos o pies asociados a infección linfática \\
\hline
\end{tabular}

16S ARNr permite identificar el agente etiológico a partir de cultivos o directamente de muestras. Esta técnica ha permitido la identificación de nuevas especies para Nocardia y Actinomadura (N. veterana, N. mexicana y A. latina). En nuestro caso, el agente etiológico se identificó con el uso de RPC universal en las colonias aisladas.

El diagnóstico diferencial de micetomas incluye tumores benignos (lipoma, fibroma, fibrolipoma) y malignos (sarcomas, sarcoma de Kaposi, melanomas) y otras infecciones como osteomielitis, tuberculosis y micosis subcutáneas como cromoblastomicosis y esporotricosis (Tabla 4).

El tratamiento de los micetomas actinomicóticos es, en general, médico (tasa de curación 60-90\%), a diferencia de los eumicetomas que requieren manejo quirúrgico asociado a antifúngicos. Se ha descrito diferentes antimicrobianos efectivos para el tratamiento del actinomicetoma, entre ellos sulfonamidas, estreptomicina, rifampicina, ciprofloxacina, tetraciclinas y dapsona; sin embargo, cotrimoxazol representa la primera línea de tratamiento y es ampliamente utilizado como monoterapia (14 mg/ $\mathrm{kg}$ /día de trimetoprim en 2 dosis $)^{12}$. En caso de alergia se puede usar eritromicina, gentamicina o doxiciclina y si hay refractariedad al tratamiento o presencia de cepas resistentes, se recomienda la asociación de antimicrobianos. En la actualidad, el uso de oxazolidinonas (linezolid) y carbapenémicos (imipenem) han mostrado ser eficaces en el manejo de lesiones resistentes o casos graves ${ }^{13-14}$. Amikacina y amoxicilina/ácido clavulánico han demos- trado efectividad en diferentes comunicaciones de casos y su uso asociado a cotrimoxazol estaría indicado en casos con compromiso óseo o diseminación pulmonar ${ }^{15-18}$. La duración del tratamiento es variable, con un promedio de 12 meses. La tasa de recidiva es más alta en pacientes que no han completado el tratamiento y la cirugía se reserva para casos refractarios a la terapia médica y compromiso óseo que no responde a la terapia conservadora ${ }^{9,19}$.

\section{Resumen}

El micetoma es una lesión subcutánea inflamatoria granulomatosa crónica causada por hongos (eumicetoma) o bacterias filamentosas (actinomicetoma). Afecta a adultos entre los 20-40 años y el sitio más comúnmente afectado es el pie. La tríada característica es un aumento de volumen del tejido afectado, con trayectos sinuosos y gránulos excretados. Comunicamos el caso de un hombre de 31 años, sano, con una historia de 6 años de un tumor asociado a trayectos sinuosos y gránulos en la región plantar izquierda. El diagnóstico clínico de micetoma fue confirmado mediante estudio microbiológico e histológico. La amplificación y secuenciación del ADN bacteriano identificó Actinomadura madurae. Es el segundo caso de actinomicetoma reportado en Chile. Consideramos importante considerar este diagnóstico en pacientes con enfermedad granulomatosa crónica asociado a trayectos sinuosos, fístulas y gránulos. 


\section{Referencias bibliográficas}

1.- Negroni R, López Daneri G, Arechavala A, Bianchi M H, Robles A M. Clinical and microbiological study of mycetomas at the Muñiz Hospital of Buenos Aires between 1989 and 2004. Rev Argent Microbiol 2006; 38: 13-8.

2.- Lupi O, Tyring S K, McGinnis M R. Tropical dermatology: fungal tropical diseases. J Am Acad Dermatol 2005; 53: 931-51.

3.- Brito A C. Micetomas. Talhari S, Garrido Neves R, editors. Dermatologia Tropical. Rio de Janeiro: Ed. Medsi; 1997, p. 203-17.

4.- Khatri M L, Al-Halali H M, Fouad Khalid M, Saif S A, Vyas M C. Mycetoma in Yemen: clinicoepidemiologic and histopathologic study. Int J Dermatol 2002; 41: 586-93.

5.- Abbott P. Mycetoma in Sudan. Trans R Soc Trop Med Hyg 1956; 50: 11-24.

6.- Mariat F, Destombes P, Segretain G. The mycetomas: clinical features, pathology, etiology and epidemiology. Contrib Microbiol Immunol 1977; 4: 1-39.

7. Gause- Niemeyer B, Fich F, Espinosa R. Nocardia asteroides Myzetom: Bahandlung mit trimethoprim/sulfamethoxazol. Dermatologie. Heute Stand Georg thiemme Verlag Stuttgart 1995; 6: 408-09.

8.- Filippi J, Quezada F, Lagos M, García P. Actinomadura madurae mycetoma of the foot. Report of one case. Rev Med Chile 2008; 136: 1448-52.

9.- Lichon V, Khachemoune A. Mycetoma: a review. Am J Clin Dermatol. 2006; 7: 315-21.

10.- Serrano JA, Sandoval AH. El micetoma. Rev Soc Ven Microbiol 2003; 23: 70-9.

11.- Daoud M, Ezzine Sebai N, Badri T, Mokhtar I, Fazza B, Kamoun M.R. Mycetoma: retrospective study of 13 cases in Tunisia. Acta Dermatovenerol Alp Panonica Adriat 2005; 14: 153-6.

12.- Tight R R, Bartlett M S. Actinomycetoma in the United States. Rev Infect Dis 1981; 3: 1139-50.

13.- Fuentes A, Arenas R, Reyes M, Fernández R F, Zacarías R. Actinomycetoma and Nocardia sp. Report of five cases treated with imipenem or imipenem plus amikacin. Gac Med Mex 2006; 142: 247-52.

14.- Moylett E H, Pacheco S E, Brown-Elliott B A,
Perry T R, Buescher E S, Birmingham M C, et al. Clinical experience with linezolid for the treatment of nocardia infection. Clin Infect Dis 2003; 36: 313-8.

15.- Welsh O, Sauceda E, González J, Ocampo J. Amikacin alone and in combination with trimethoprim-sulfamethoxazole in the treatment of actinomycotic mycetoma. J Am Acad Dermatol 1987; 17: 443-8.

16.- Kashima M, Kano R, Mikami Y, Takahama H, Ito M, Hasegawa A, et al. A successfully treated case of mycetoma due to Nocardia veterana. Br J Dermatol 2005; 152: 1349-52.

17.- Sharma N, Mendiratta V, Sharma RC, Hemal U, Verma M. Pulse therapy with amikacin and dapsone for the treatment of actinomycotic foot: a case report. J Dermatol 2003; 30: 742-7.

18.- Gómez A, Saul A, Bonifaz A, López M. Amoxicillin and clavulanic acid in the treatment of actinomycetoma. Int J Dermatol 1993; 32: 218-20.

19.- Ameen M, Arenas R. Developments in the management of mycetomas. Clin Exp Dermatol 2009; 34: 1-7. 